\title{
Large-Scale Spherical Silicon Solar Cell for Advanced Light Management
}

\author{
Nazek El-Atab \\ mmh Labs, Computer, Elecctrical \\ and Mathematical Sciences and \\ Engineering Division \\ King Abdullah University of \\ Science and Technology \\ Thuwal, Saudi Arabia \\ nazek.elatab@kaust.edu.sa
}

\author{
Nadeem Qaiser \\ mmh Labs, Computer, Elecctrical \\ and Mathematical Sciences and \\ Engineering Division \\ King Abdullah University of \\ Science and Technology \\ Thuwal, Saudi Arabia \\ nadeem.qaiser@kaust.edu.sa
}

\author{
Rabab Bahabry \\ Department of Physics, \\ University of Jeddah, Jeddah, \\ 21589-80200, Saudi Arabia \\ rabab.bahabry@kaust.edu.sa
}

\author{
Muhammad Mustafa Hussain \\ mmh Labs, Computer, Elecctrical \\ and Mathematical Sciences and \\ Engineering Division \\ King Abdullah University of \\ Science and Technology \\ Thuwal, Saudi Arabia \\ Elecctrical Engineering and \\ Computer Science \\ University of California, Berkeley \\ California, USA \\ muhammad.hussain@kaust.edu.s \\ a \\ mmhussain@berkeley.edu
}

\begin{abstract}
In order to realize a high power conversion efficiency, a solar cell should effectively utilize most of the incoming photons. Here, we demonstrate a spherical shaped solar cell that is capable of capturing direct, diffuse and background reflected light without the need for a mechanical sun-tracking tool. The spherical cell is based on monocrystalline silicon with an efficiency of $19 \%$ ad is developed using a corrugation technique to achieve flexibility in otherwise rigid silicon. The obtained spherical cell is large scale with a diameter of around $4 \mathrm{~cm}$. Theoretical calculations in addition to experimental results confirm the merits of the spherical solar cell which shows an increase in instantaneous power output by $14.8 \%$ and $39.7 \%$ with respect to a traditional flat cell with the same ground area when sand and white paper are used as reflective background materials, respectively. Finally, the spherical shaped cell shows advantages in terms of lower dust accumulation rate due to its downward orientation.
\end{abstract}

Keywords—silicon, corrugation, light management, background reflection, $P V$.

\section{INTRODUCTION}

Silicon is still considered as the material of choice in PV industry due to its good efficiency and excellent reliability in solar cells, mature and low-cost manufacturing processes, in addition to its natural abundancy [1-2]. However, the commercially available silicon solar cells are approaching the theoretical limit. Consequently, research on silicon PV is mainly focused on developing lower cost manufacturing processes, novel light trapping and integration schemes, in addition to efficient material utilization methods. Unconventional architectures to further exploit silicon in PV research are valuable in this context [1-7].

Previously, spherical silicon solar micro-cells with an efficiency of $10 \%$ were demonstrated in an attempt to capture direct, diffuse and reflected light more efficiently. However, the micro-cells were fabricated on a planar substrate, which hinders the absorption of the reflected light from the background [8-9]. The results presented in this work show that a large-scale spherical shaped solar cell is capable of increasing the power output with respect to a conventional flat cell with an identical ground area, thanks to its capability to naturally track the sunlight during the day and throughout the year in addition to being able to collect the background reflected light.

\section{FABRICATION}

The spherical solar cells is developed using a corrugation process where alternating grooves are patterned using a $\mathrm{CO}_{2}$ laser and etched in a deep reactive ion etching system (DRIE) to achieve flexibility in otherwise rigid $170 \mu \mathrm{m}$-thick solar cells (Fig. 1) [10-13]. The method is applied on wafer-scale silicon photovoltaic devices with interdigitated back contacts (IBC). The process results in flexible cells with negligible decline in the electrical performance (efficiency of 19\%).

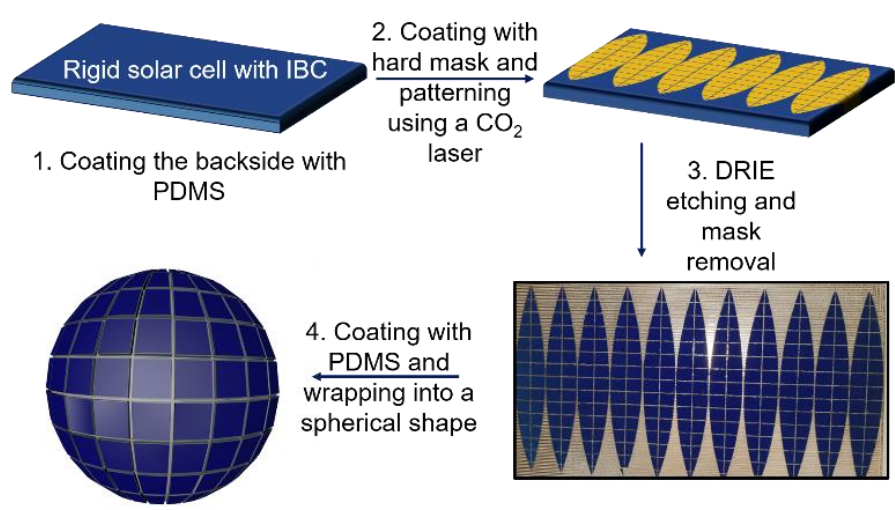

Fig. 1. Illustration of the corrugation-based process of the spherical solar cell. 
Polydimethylsiloxane is then used to encapsulate the corrugated cell. Finally, the obtained flexible and flat solar cell is wrapped into a spherical shape to achieve a $4-\mathrm{cm}$ diameter spherical solar cell. Due to the corrugation technique, the loss of active silicon area within the grooves is around $20 \%$ compared to its rigid version.

\section{RESULTS AND DISCUSSION}

\section{A. Theoretical Calculations}

The total incident radiation on a solar cell is generally expressed as the summation of three components: direct beam, diffuse beam and reflected beam. Using the isotropic diffuse model, the total incident radiation $\left(\mathrm{I}_{\mathrm{T}}\right)$ on a tilted solar cell can be expressed as:

$$
\mathrm{I}_{\mathrm{T}}=\mathrm{I}_{\mathrm{b}} \mathrm{R}_{\mathrm{b}}+\mathrm{I}_{\mathrm{d} .} \mathrm{F}_{\text {sky }}+\mathrm{I} . \rho_{\text {ground. }} \mathrm{F}_{\text {ground }}
$$

where $I_{b}$ is the direct beam radiation, $R_{b}$ is the geometric factor defined by the ratio of the beam radiation on the tilted surface to that on a horizontal surface at any time, $I_{d}$ is the diffuse radiation, $\mathrm{F}_{\text {sky }}$ is the sky view factor, $\mathrm{I}$ is the total radiation on a horizontal surface, $\rho_{\text {ground }}$ is the diffuse reflectance of the ground and $F_{\text {ground }}$ is the ground view factor. ${ }^{33-34}$

In terms of direct beam, a spherical solar cell behaves as a flat light-tracking solar cell with an effective area equal to one fourth of the total spherical area (i.e. $\pi \mathrm{R}^{2}$ ). While in terms of diffuse and reflected beam, it acts as a horizontal and vertical flat solar cell, respectively, with an effective area equal to half the total area of the sphere as shown in Figs. 2a-c. This clearly shows the advantages of a spherical solar cell over a flat one with the same ground area (i.e. $\pi R^{2}$ ) in terms of total solar insolation.

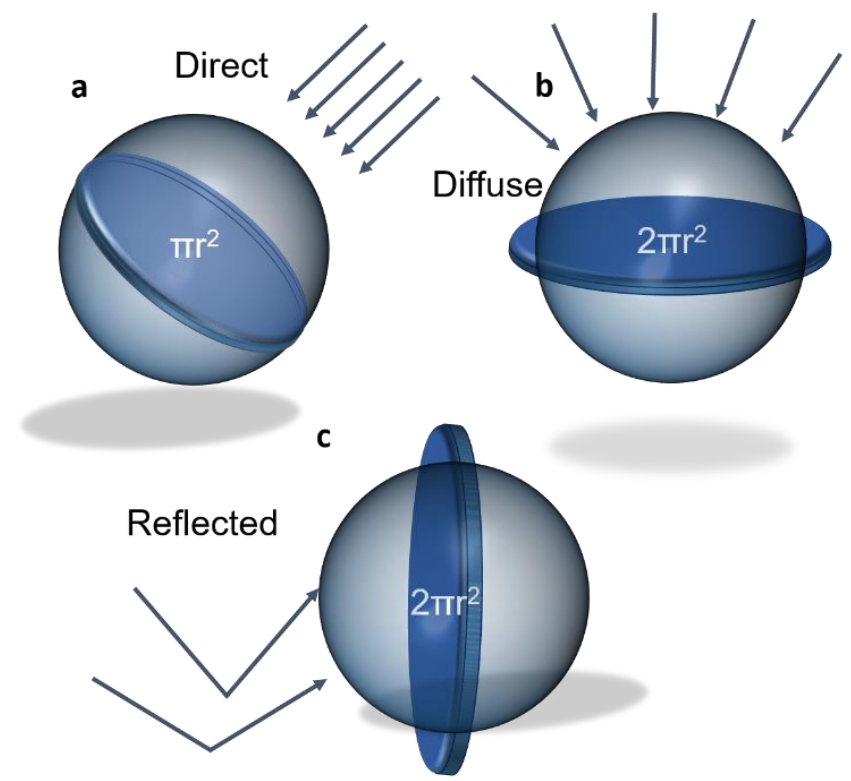

Fig. 2. (a) Spherical solar cell representation in terms of direct beam, the spherical cell behaves as a flat cell with the same ground area and that is constantly tracking the light. (b) Spherical solar cell representation in terms of diffuse beam, spherical cell behaves as a horizontal flat cell with twice the ground area. (c) Spherical solar cell representation in terms of reflected beam, spherical cell acts as a vertical cell with twice the ground area.
Theoretical calculations have been conducted on the hourly direct beam received by a spherical solar cell vs. flat solar cell with the same ground area $\left(1 \mathrm{~m}^{2}\right)$ using $\mathrm{I}, \mathrm{I}_{\mathrm{b}}$ and $\mathrm{I}_{\mathrm{d}}$ data published by NREL. ${ }^{35}$ The total area of the spherical solar cell is assumed to be reduced by $20 \%$ due to the corrugation technique. It is also important to mention that the effective area of the flat solar cell varies throughout the day as the orientation of the sun changes resulting in non-perpendicular incident beams on the surface of the cell according to the following equation:

$$
\mathrm{A}_{\text {eff }}=\mathrm{A} \times \cos \theta
$$

where $\mathrm{A}$ is the actual area of the flat solar cell and $\theta$ is the incidence angle of the direct beam, while the effective area of the spherical cell remains constant (Figs. 3a). The results confirm that, even though the flat solar cell shows a higher direct beam insolation around noon due to its larger effective area, however, the total integrated direct beam insolation received by the spherical cell per day is $31.8 \%$ higher than that collected by the flat cell with the same ground area (Fig. 3b). This is due to the capability of the spherical solar cell to track the sun during the day and therefore capture the direct beam with the highest efficiency.
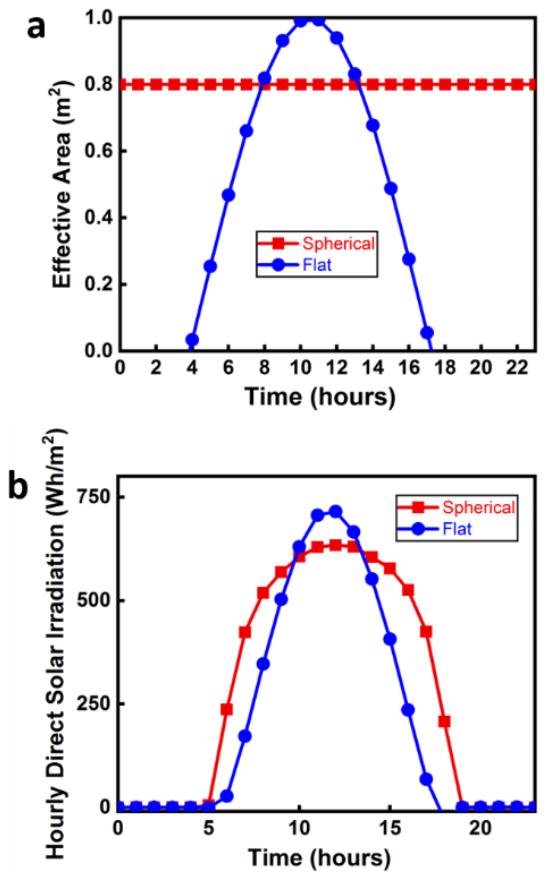

Fig. 3. (a) Effective area of both spherical and flat solar cells throughout the day, the corrugation technique is assumed to reduce the total area of the spherical solar cell by $20 \%$. The effective area of the flat solar cell is equal to its actual area multiplied by the cosine of the beam angle of incidence. The effective area of the spherical solar cell is fixed due to its symmetrical shape. (b) Theoretically calculated hourly direct irradiation received by the spherical and flat solar cells with the same ground area $\left(1 \mathrm{~m}^{2}\right)$ using NREL data. 


\section{B. Experimental Results}

The developed spherical solar cell is characterized under a solar simulator in air (AM 1.5 Global Spectrum with $1000 \mathrm{~W}$ $\mathrm{m}^{-2}$ intensity and spectral mismatch correction at the room temperature). The initial temperature of the cell is preconditioned at $21^{\circ} \mathrm{C}$. The cell is then held at a height of around $2 \mathrm{~cm}$ while different reflective background materials are used including white paper and sand to study the albedo effect as shown in Fig. 4. A circular rigid solar cell with the same ground area $\left(11.34 \mathrm{~cm}^{2}\right)$ is also characterized under the same conditions. The results show that the spherical cell provides an increase in instantaneous power output by $14.8 \%$ and $39.7 \%$ with respect to the traditional flat solar cell with the same ground area $\left(11.34 \mathrm{~cm}^{2}\right)$ when sand and white paper are used as reflective background materials, respectively. The increase in power output is due to the increased surface area of the solar cell that is exposed to light.

It is also worth to note that due to the downward orientation of a spherical cell, the rate of dust accumulation is lower than in the case of a flat cell with the same ground area. As a matter of fact, accumulated dust particles contribute to photons scattering instead of their absorption by the solar cell leading to a deterioration in the device efficiency.
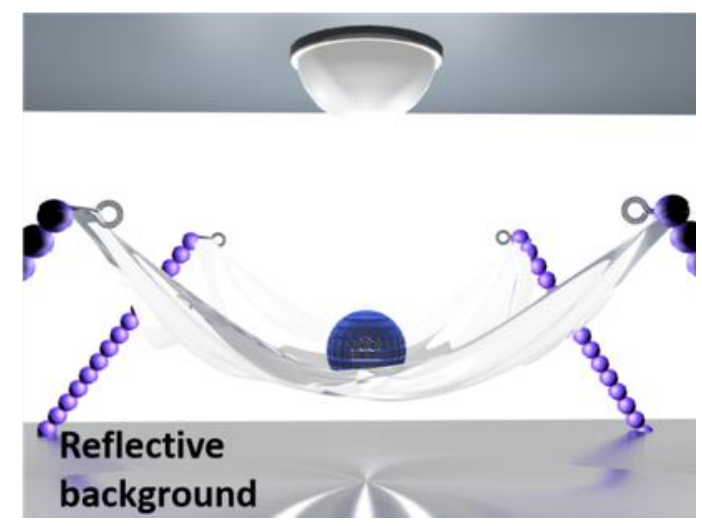

Fig. 4. Measurement setup with white paper and sand reflective backgrounds.

\section{CONCLUSION}

In order to capture light more efficiently from the same ground area, a silicon based spherical shaped solar cell with an efficiency of $19 \%$ is demonstrated. The solar cell is developed using a corrugation technique that results in flexible cells with no noticeable deterioration in the original performance. Theoretical calculations show that the spherical cell enables light-tracking and thus, the harvesting of direct and diffuse beams with a higher efficiency compared to a conventional flat cell with the same ground area. As a result, an increase in the power output by around $31.8 \%$ per day is calculated. Finally, experimental results confirmed the merits of a spherical shaped cell where background reflected light from sand and white paper increase the instantaneous power output by $14.8 \%$ and $39.7 \%$, respectively.

\section{REFERENCES}

[1] J. Yoon et al., "Flexible concentrator photovoltaics based on microscale silicon solar cells embedded in luminescent waveguides", Nature Communications, vol. 2, no. 1, 2011. Available: 10.1038/ncomms1318.

[2] M. Branham et al., "Silicon Solar Cells: 15.7\% Efficient 10- $\mu \mathrm{m}-$ Thick Crystalline Silicon Solar Cells Using Periodic Nanostructures (Adv. Mater. 13/2015)", Advanced Materials, vol. 27, no. 13, pp. 2268-2268, 2015. Available: 10.1002/adma.201570092.

[3] A. Rahman et al., "Sub-50-nm self-assembled nanotextures for enhanced broadband antireflection in silicon solar cells", Nature Communications, vol. 6, no. 1, 2015. Available: 10.1038/ncomms6963.

[4] P. Campbell and M. Green, "High performance light trapping textures for monocrystalline silicon solar cells", Solar Energy Materials and Solar Cells, vol. 65, no. 1-4, pp. 369-375, 2001. Available: 10.1016/s09270248(00)00115-x.

[5] K. Weber et al., "A Novel Low-Cost, High-Efficiency Micromachined Silicon Solar Cell", IEEE Electron Device Letters, vol. 25, no. 1, pp. 3739, 2004. Available: 10.1109/led.2003.821600.

[6] J. Yoon et al., "Ultrathin silicon solar microcells for semitransparent, mechanically flexible and microconcentrator module designs", Nature Materials, vol. 7, no. 11, pp. 907-915, 2008. Available: 10.1038/nmat2287.

[7] C. Sah, "High efficiency crystalline silicon solar cells", Solar Cells, vol. 17, no. 1, pp. 1-27, 1986. Available: 10.1016/0379-6787(86)90056-6.

[8] T. Minemoto, C. Okamoto, S. Omae, M. Murozono, H. Takakura and Y. Hamakawa, "Fabrication of Spherical Silicon Solar Cells with SemiLight-Concentration System", Japanese Journal of Applied Physics, vol. 44, no. 7, pp. 4820-4824, 2005. Available: 10.1143/jjap.44.4820.

[9] T. Maruyama and H. Minami, "Light trapping in spherical silicon solar cell module", Solar Energy Materials and Solar Cells, vol. 79, no. 2, pp. 113-124, 2003. Available: 10.1016/s0927-0248(02)00375-6.

[10] N. El-Atab, N. Qaiser, R. Bahabry and M. Hussain, "Corrugation Enabled Asymmetrically Ultrastretchable (95\%) Monocrystalline Silicon Solar Cells with High Efficiency (19\%)", Advanced Energy Materials, vol. 9, no. 45, p. 1902883, 2019. Available: 10.1002/aenm.201902883.

[11] N. El-Atab, W. Babatain, R. Bahabry, R. Alshanbari, R. Shamsuddin and M. Hussain, "Ultraflexible Corrugated Monocrystalline Silicon Solar Cells with High Efficiency (19\%), Improved Thermal Performance, and Reliability Using Low-Cost Laser Patterning", ACS Applied Materials \& Interfaces, 2019. Available: 10.1021/acsami.9b15175.

[12] R.R. Bahabry, A.T. Kutbee, S.M. Khan, A.C. Sepulveda, I Wicaksono, M. Nour, N. Wehbe, A.S Almislem, M.T. Ghoneim, G.A. Torres Sevilla, A. Syed, S.F. Shaikh, M.M. Hussain. Advanced Energy Materials 2018, 8, 1702221 .

[13] N. El-Atab, R. Shamsuddin, R. Bahabry, and M.M.Hussain "HighEfficiency Corrugated Monocrystalline Silicon Solar Cells with MultiDirectional Flexing Capabilities" 46th IEEE PVSC, 1499-1501 